J. Lake Sci.(湖泊科学), 2008, 20(5): 563-570

http://www.jlakes.org. E-mail: jlakes@niglas.ac.cn

(C)2008 by Journal of Lake Sciences

\title{
贵州省草海表层水体和沉积物间隙水中录的含量和形态分布初步研究
}

\author{
钱晓莉 ${ }^{1,2}$, 冯新斌 $2^{2 * *}$, 闭向阳 ${ }^{2,3}$, 何天容 ${ }^{2,3}$, 郭艳娜 ${ }^{2,3}$, 付学吾 ${ }^{2,3}$, 李 平 2,3 \\ (1: 贵州大学资源与环境工程学院, 贵阳 550003) \\ (2: 中国科学院地球化学研究所环境地球化学国家重点实验室, 贵阳 550002) \\ (3: 中国科学院研究生院, 北京 100049)
}

摘 要: 运用金永齐-冷原子苂光光谱法(CVAFS)和气相色谱技术 $(\mathrm{GC})$, 对贵州省草海不同水文季节(枯水期和丰水期)表层水 中永的各种赋存形态，包括总永 $(\mathrm{HgT})$ 、溶解态永 $(\mathrm{HgD})$ 、活性永 $(\mathrm{HgR})$ 、颗粒态永 $(\mathrm{HgP})$ 、总甲基永 $(\mathrm{MeHgT})$ 、溶解态甲基永 $(\mathrm{MeHgD})$ 和颗粒态甲基永 $(\mathrm{MeHgP})$ 以及沉积物间隙水剖面中的溶解态总永和甲基永含量进行了测定. 结果显示: 草海表层水 体总录浓度为 $1.7-9.0 \mathrm{ng} / \mathrm{L}$, 活性永浓度为 $0.06-1.4 \mathrm{ng} / \mathrm{L}$, 总甲基永浓度为 $0.11-0.67 \mathrm{ng} / \mathrm{L}$. 沉积物间隙水中溶解态录浓度为 8.6-39.6ng $/ \mathrm{L}$, 溶解态甲基永浓度为 0.11-4.9ng/L. 实验数据表明, 草海湖水以溶解态永为主, 其占总永的比例为枯水期 $87 \%$, 丰水期 $51 \%$, 溶解态录与总永呈显著相关(丰水期 $P<0.01$; 枯水期 $P<0.05$ ), 颗粒态录与总永也呈显著相关(丰水期 $P<0.01$; 枯 水期 $P<0.05$ ). 溶解态甲基永与总甲基永呈显著相关（丰水期 $P<0.01$; 枯水期 $P<0.05$ ), 表明溶解态甲基永控制总甲基永的分布. 沉积物间隙水溶解态永与溶解态甲基永浓度明显高于上覆水体, 表明沉积物为草海湖水中录的一个重要来源.

关键词: 永形态; 表层水; 间隙水; 含量分布; 草海

\section{Concentrations and distributions of mercury species in surface water and porewater of Lake Caohai, Guizhou Province}

\author{
QIAN Xiaoli ${ }^{1,2}$, FENG Xinbin ${ }^{2}$, BI Xiangyang ${ }^{2,3}$, HE Tianrong ${ }^{2,3}$, GUO Yanna ${ }^{2,3}$, FU Xuewu ${ }^{2,3}$ \& LI Ping Pi, $^{2,3}$ \\ (1: College of Resources and Environment, Guizhou University, Guiyang 550003, P.R.China) \\ (2: State Key Laboratory of Environmental Geochemistry, Institute of Geochemistry, Chinese Academy of Sciences, Guiyang 550002, \\ P.R.China) \\ (3: Graduate School of Chinese Academy of Sciences, Beijing 100049, P.R.China)
}

\begin{abstract}
Abatract: Concentrations and distributions of various mercury $(\mathrm{Hg})$ species, including total $\mathrm{Hg}(\mathrm{HgT})$, dissolved $\mathrm{Hg}(\mathrm{HgD})$, reactive $\mathrm{Hg}(\mathrm{HgR})$, particulate $\mathrm{Hg}(\mathrm{HgP})$, total methylmercury $(\mathrm{MeHgT})$, dissolved methylmercury (MeHgD), and particulate methylmercury $(\mathrm{MeHgP})$ in surface water and porewater of the sediment collected from Lake Caohai during the flood and dry seasons were analyzed by using CVAFS and GC techniques. The concentrations of $\mathrm{HgT}$ ranged from 1.7 to $9.0 \mathrm{ng} / \mathrm{L}, \mathrm{HgR}$ from 0.06 to $1.4 \mathrm{ng} / \mathrm{L}$, and $\mathrm{MeHgT}$ from 0.11 to $0.67 \mathrm{ng} / \mathrm{L}$ in surface water, respectively. In the sediment porewater, the concentrations of $\mathrm{HgD}$ varied from 8.6 to 39.6ng/L, and MeHgD ranged from 0.11 to $4.9 \mathrm{ng} / \mathrm{L}$. The Hg species in surface water was mostly dominated with dissolved forms with an average of $87 \%$ of $\mathrm{HgT}$ in dry flow period and $51 \%$ of $\mathrm{HgT}$ in flood flow period, respectively. The $\mathrm{HgD}$ and $\mathrm{HgP}$ forms were significantly correlated with $\mathrm{HgT}$. The $\mathrm{MeHgD}$ were positively correlated to $\mathrm{MeHgT}$, showing that distributions of MeHgT were controlled by $\mathrm{MeHgD}$. Concentrations of $\mathrm{HgD}$ and $\mathrm{MeHgD}$ in porewater were higher than that obtained in the underlying water, which suggestted that the sediment was a dominant $\mathrm{Hg}$ source to the lake.

Keywords: Mercury species; surface water; porewater; concentrations and distributions; Lake Caohai
\end{abstract}

* 国家自然科学基金重点项目(40532014)资助. 2007-07-16 收稿; 2007-10-12 收修改稿. 钱晓莉, 女, 1978 年生, 硕士, 讲 师; E-mail: xiaoliroap2000@163.com.

** 通讯作者; E-mail: fengxinbin@vip.skleg.cn. 
采是人体的有毒、非必需元素，甲基永是不同形态永中毒性最强的一种形态. 20 世纪 50 年代举世震 惊的日本 “水俣病” 事件就是由于甲基永中毒造成的. 水生态系统是发生录甲基化和生物累积效应的重 要场所. 20世纪 80-90 年代，人们陆续在北美和北欧的偏远湖泊中发现，甲基录在食物链中能产生强烈的 生物累积效应 ${ }^{[1-3]}$, 在这些湖泊鱼体中甲基永含量显著升高. 因此, 对湖泊水体中录污染的研究成为环境 领域关注的焦点之一.

草海高原湿地属于长江水系，位于贵阳以西约 $350 \mathrm{~km}$ ，是贵州省境内最大的天然岩溶堰塞淡水湖，湖 水补给主要以大气降水 ${ }^{[4]}$, 因此大气沉降输人是草海高原湿地系统中重金属污染物的一个重要途径. 由 于贵州赫章县著名的土法炼锌集中区距草海仅十多千米, 土法炼锌排放大量的 $\mathrm{Hg}^{0}$ 可随大气环流进行迁 移并经干湿沉降进人水生生态系统，从而对水体造成严重的永污染 ${ }^{[5]}$, 这无疑对草海水生生态系统产生 重要影响. 本文以草海为研究对象, 分析了不同水文季节湖水及沉积物间隙水中求的赋存状态及其时空 分布, 尤其是甲基永的含量变化特征, 初步探讨了周围土法炼锌及其它人为活动对草海水体录分布的影 响, 对深人了解草海湖泊录的生物地球化学行为及环境效应具有重要的指导意义, 同时可以为我国其它 湖泊系统中录的研究提供基础数据.

\section{1 样品的采集与分析}

\section{1 样品的采集}

从草海进水口到出水口, 共设置了 11 个水样采集点. 枯水期采样于 2005 年 10 月进行, 从上游到下 游设 5 个采样点; 丰水期采样于 2006 年 6 月进行，从上游到下游采集 11 个点; 另外，同时在人湖区和湖 心区进行沉积物及间隙水的采集(图 1).

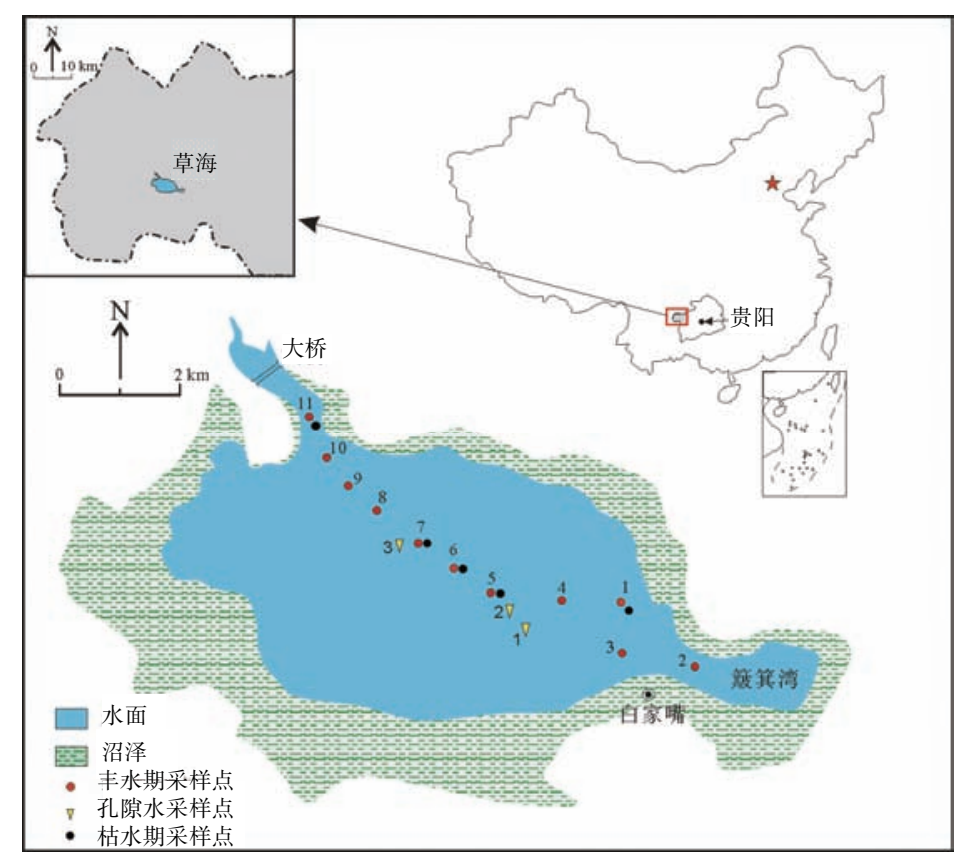

图 1 草海湖泊采样点分布

Fig.1 Sampling sites in Lake Caohai

1.1 .1 水样的采集 采集时面向水流方向, 在船上方采样. 样品采于水面以下约 $20 \mathrm{~cm}$. 使用硼硅玻璃瓶或 聚四氟乙烯瓶采集水样. 采样前所有器血和滤膜 $(0.45 \mu \mathrm{m}$ 尼龙滤膜)均经过超净处理, 按 $10 \%$ 的比例随机抽 取测定空白, 确定空白合格后方可带至野外使用. 不过滤样品直接装人 $100 \mathrm{ml}$ 嗍硅玻璃瓶内, 装样前, 用 
少量样品洗涤 3 次. 采集的水样按 $0.5 \%(\mathrm{~V} / \mathrm{V})$ 的比例 $24 \mathrm{~h}$ 内加人亚沸蒸馏的 $12 \mathrm{~mol} / \mathrm{L} \mathrm{HCl}$, 双层塑料袋包 装后放人木箱运回实验室 $4^{\circ} \mathrm{C}$ 下保存. 过滤样品现场用 $0.45 \mu \mathrm{m}$ 滤膜过滤后和未过滤水一样处理保存. 为 避免人为污染, 所有操作过程均使用一次性聚乙烯手套.

1.1.2 沉积物间隙水的采集 采用 SWB-1 型便携式、不扰动湖泊沉积物采样器采集沉积物柱. 采样过程中, 需要保证沉积物柱界面水清澈、表层沉积物完好、整个沉积物松散均匀 ${ }^{[6]}$. 沉积物采集后抽取界面水(保 存方法与湖水相同), 然后进行分割. 沉积物样品在现场通过氮气厌氧条件下 $10 \mathrm{~cm}$ 以上按 $1 \mathrm{~cm}$ 间距分割, $10 \mathrm{~cm}$ 以下按 $2 \mathrm{~cm}$ 间隔分割, 将样品封存人经酸处理的 $50 \mathrm{ml}$ 塑料离心管, 用 Parafilm 密封, 低温 $4^{\circ} \mathrm{C}$ 保存, $48 \mathrm{~h}$ 内用离心方式提取间隙水 $\left(4^{\circ} \mathrm{C}\right.$ 恒温、转速 $3000 \mathrm{r} / \mathrm{min}$ 、离心 $\left.30 \mathrm{~min}\right)$ ，间隙水经 $0.45 \mu \mathrm{m}$ 滤膜过滤并装人 事先处理好的硣硅比色管, 加 $0.5 \%$ 盐酸密封保存于冰箱中待测定 ${ }^{[7]}$.

\section{2 样品的分析}

总录形态测定: 总永和溶解态永, 分别取未过滤水样和过滤水样各 $50 \mathrm{ml}$, 经浓度为 $9.0 \mathrm{~mol} / \mathrm{L}$ 的氯化 溴 $500 \mu \mathrm{l}$ 氧化后, 用浓度为 $3.6 \mathrm{~mol} / \mathrm{L}$ 的盐酸差胺 $200 \mu \mathrm{l}$ 除去其中游离的卤素, 用浓度为 $2.0 \mathrm{~mol} / \mathrm{L}$ 的氯化 亚锡 $100 \mu \mathrm{l}$ 将所有的 $\mathrm{Hg}^{2+}$ 还原为 $\mathrm{Hg}^{0}$, 再由氮气将 $\mathrm{Hg}^{0}$ 吹扫捕集于金管上，用冷原子苂光光谱法 (Tekran 2500 测永仪)进行测定. 活性永用浓度为 $2.0 \mathrm{~mol} / \mathrm{L}$ 的氯化亚锡 $100 \mu \mathrm{l}$, 直接还原未过滤水样后, 用冷原子 苂光光谱法进行测定 ${ }^{[8]}$. 颗粒态采为总永与溶解态永的差值. 实验方法的最低检测限为 $0.02 \mathrm{ng} / \mathrm{L}$, 样品加 标回收率平均为 $93.0 \%-110.1 \%$.

甲基录测定：总甲基永和溶解态甲基永分别取未过滤和过滤的水样, 采用蒸馏-乙基化 GC-CVAFS 法测 定 ${ }^{[7]}$. 颗粒态甲基永为总甲基永与溶解态甲基永的差值. 该方法的最低检测限为 $0.009 \mathrm{ng} / \mathrm{L}$, 加标回收率为 $88.2 \%-108.4 \%$.

\section{2 结果}

\section{1 表层水中不同形态录分布}

2.1 .1 表层水体总泉、溶解态录、颗粒态录与活性泉的分布 图 2 显示了草海表层水体总录、颗粒态录及 溶解态录的分布. 草海表层水体总永浓度为 1.7-9.0ng/L, 平均浓度为 $5.3 \mathrm{ng} / \mathrm{L}$, 明显高于世界其它天然水 体一倍甚至几倍 ${ }^{[-16]}$ (表 1), 这可能与以下区域背景和人为活动有关: 近年来贵州省燃煤导致了严重的大 气污染，进人大气的录通过干湿沉降可造成湖泊水体内求浓度偏高 ${ }^{[17-18]}$; 另外，在离草海 $10 \mathrm{~km}$ 的赫章县 妈姑镇有大量的土法炼锌活动，从 1989-2001 年间，土法炼锌活动向妈姑镇 (150km² 范围内)大气中释放 永就达 $46 \mathrm{t}^{[19]}$. 大气录会通过长距离输送至数百公里范围, 经大气干湿沉降到周围湖泊水体而造成严重 的录污染 ${ }^{[5]}$. 这可能是导致草海湖泊水体永含量高于世界其它天然湖泊的重要因素之一. 但是, 与贵州 省的红枫湖、百花湖、啊哈水库等研究结果相比较(表 1)，草海总永含量比同区域背景的几个湖泊低. 原 因是相同区域背景条件下，其它湖泊均具有直接的、多途径的录污染源 ${ }^{[9-11]}$.

丰水期草海表层水体总录浓度变化为 1.6-6.7ng/L, 平均值为 $3.5 \mathrm{ng} / \mathrm{L}(n=11)$, 枯水期浓度变化为 5.9-9.0ng/L, 平均值为 $7.1 \mathrm{ng} / \mathrm{L}(n=5)$. 不同季节表现为枯水期 $>$ 丰水期. 分析原因是: 丰水期大量的水生植物对重金属 有净化作用 ${ }^{[20]}$, 因此降低了水体中永含量; 此外, 丰水期水体温度较高, 光照较强, 水体表面永释放强度 增大，从而降低了水体录的负荷 ${ }^{[21-22]}$. 相对而言，枯水期采样属于取暖季，取暖活动造成的化石燃料使 用量的增加以及冷季不利于大气录扩散的气候背景, 导致大气中不同形态录含量的显著升高，而高含量 的大气录通过干湿沉降向湖泊水体的输入是造成枯水期水体总永浓度升高的一个主要原因. 另外, 枯水 期水体生物大量死亡，微生物活动降低，降低了水生植物对水体的净化作用，从而导致枯水期水体永含 量上升

对比草海水体总永空间分布特征发现，进出口处水体永含量高，湖心相对低. 主要原因是进出口处 受人为活动影响(如生活生产废水等大量排放和周围农田种植)所致. 其中采样点 $1 、 2$ 等曾经遭受炼锌废 水和电厂废水的污染，尽管已经停止排放，但是永含量仍相对较高，因此，潜在污染源(录矿、煤矿等)对 水体存在一定影响. 此外, 草海丰富水生植物的自净作用使水中永含量从上游到下游出现降低的趋势, 尤其在丰水期表现更为明显. 
草海表层水体颗粒态永浓度为 $0.40-3.1 \mathrm{ng} / \mathrm{L}$, 平均值 $1.4 \mathrm{ng} / \mathrm{L}$. 丰水期颗粒态录浓度变化为 $0.83-3.1 \mathrm{ng} / \mathrm{L}$, 平均为 $1.7 \mathrm{ng} / \mathrm{L}$, 占总永的比例变化为 $25 \%-74 \%$, 平均为 $48 \%(n=11)$, 并与总录存在极显著相关性 $(P<0.01)$. 枯水期颗粒态采浓度变化为 $0.4-2.3 \mathrm{ng} / \mathrm{L}$, 平均值为 $1.0 \mathrm{ng} / \mathrm{L}$, 占总录的比例变化为 $6 \%-25 \%$, 平均值为 $13 \%(n=5)$ (图 2). 在枯水期颗粒态永对总永贡献率明显下降，说明季节的变化会显著影响水体中颗粒态永 含量变化，进而影响颗粒态寽对总采的贡献率. 在丰水期，地表径流携带陆地的微细颗粒进入湖泊，颗 粒物对永的强烈吸附作用使湖泊颗粒态永含量明显增高; 同时草海较浅，丰水期湖水动力增强，扰动河 底沉积物, 使湖泊表层沉积物再悬浮, 将沉积物中的寽转变为悬浮态录. 这两种作用共同提高了水体中 颗粒态采的含量 ${ }^{[22]}$. 颗粒态永含量的空间变化特征为: 进出口高(最大值为 $3.1 \mathrm{ng} / \mathrm{L}$ ), 湖心、下游相对较低. 主要是进出口人为活动较大, 颗粒物主要来源于生活污水、农田污水等排放, 水体颗粒物含量较高, 而远 离人为活动频繁区域后, 湖水动力条件随着环境条件改变而发生变化, 湖水流速逐渐平稳, 导致水中悬 浮颗粒物在湖泊沿途沉降至河床底层，使表层水体颗粒态永含量降低，因此，湖心和下游区域颗粒态采 含量明显降低.
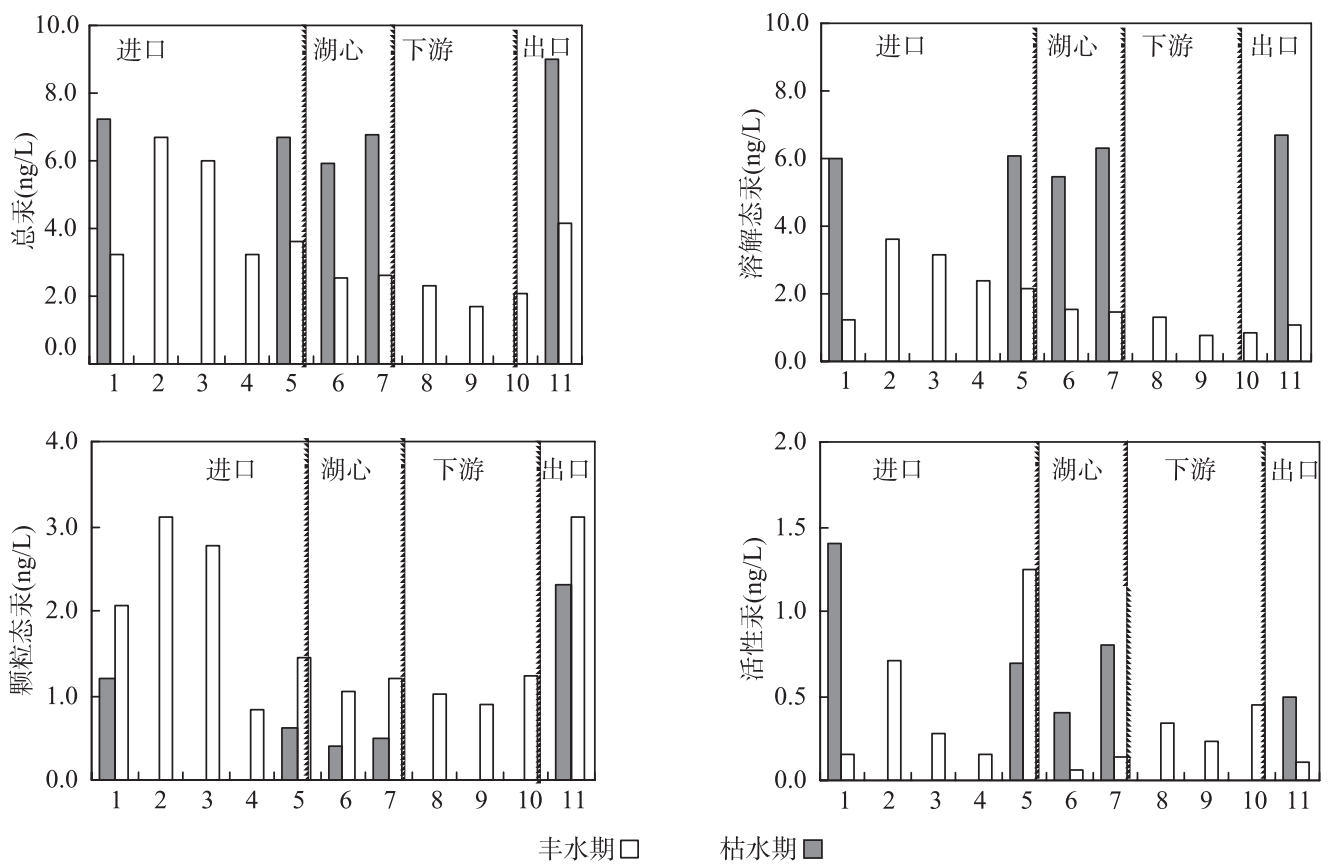

图 2 草海表层水体总永、溶解态采、颗粒态永与活性永的分布

Fig.2 Distributions of $\mathrm{HgT}, \mathrm{HgD}, \mathrm{HgP}$ and $\mathrm{HgR}$ in surface water in Lake Caohai

草海表层水体溶解态采含量介于 $0.80-6.7 \mathrm{ng} / \mathrm{L}$ 之间, 平均值为 $3.9 \mathrm{ng} / \mathrm{L}$. 丰水期溶解态采的浓度范围 为 $0.8-3.6 \mathrm{ng} / \mathrm{L}$, 平均为 $1.8 \mathrm{ng} / \mathrm{L}(n=11)$; 枯水期浓度范围为 5.2-6.7ng/L, 平均为 $6.1 \mathrm{ng} / \mathrm{L}(n=5)$. 不同季节表 现为枯水期 $>$ 丰水期，与总采的分布趋势一致. 草海溶解态采占总永的比例较大，丰水期溶解态永/总永 为 $25 \%-74 \%$, 平均为 $51 \%$, 溶解态寽与总永的相关性达极显著水平 $(P<0.01)$; 而枯水期水质清澈, 悬浮物 浓度降低，对永的吸附作用也降低，因此，溶解态永占总永的比例上升，溶解态永/总永为 $74 \%-93 \%$, 平 均为 $87 \%$, 枯水期溶解态寽与总采含量之间达到显著相关 $(P<0.05)$.

草海表层水体活性永含量介于 $0.06-1.4 \mathrm{ng} / \mathrm{L}$ 范围, 平均值为 $0.58 \mathrm{ng} / \mathrm{L}$. 丰水期活性永浓度范围为 $0.05-1.23 \mathrm{ng} / \mathrm{L}$, 平均值为 $0.35 \mathrm{ng} / \mathrm{L}, \mathrm{HgR} / \mathrm{HgT}$ 的范围为 $2 \%-3.4 \%(n=11)$. 枯水期活性永对总录的贡献率有所上 升, 为 $6 \%-19 \%$. 枯水期活性永范围为 $0.4-1.4 \mathrm{ng} / \mathrm{L}$, 平均值为 $0.80 \mathrm{ng} / \mathrm{L}(n=5)$ (图 2). 不同季节活性永的浓度为枯 水期约高于丰水期, 与总永分布趋势一致, 主要受冬季取暖活动、夏季水生微生物活动等共同因素影响. 
表 1 草海水体中不同形态录含量与其他地区水体的比较(单位: $\mathrm{ng} / \mathrm{L}$ )

Tab.1 Comparison of different speciation of $\mathrm{Hg}$ in Lake Caohai and the other water worldwide

\begin{tabular}{|c|c|c|c|c|c|c|c|}
\hline 水体 & $\begin{array}{l}\text { 总求 } \\
(\mathrm{HgT})\end{array}$ & $\begin{array}{c}\text { 颗粒态丞 } \\
(\mathrm{HgP})\end{array}$ & $\begin{array}{c}\text { 溶解态求 } \\
(\mathrm{HgD})\end{array}$ & 水体 & $\begin{array}{l}\text { 总永 } \\
(\mathrm{HgT})\end{array}$ & $\begin{array}{r}\text { 颗粒态求 } \\
(\mathrm{HgP})\end{array}$ & $\begin{array}{c}\text { 溶解态永 } \\
(\mathrm{HgD})\end{array}$ \\
\hline 草海 & $1.7-9.0$ & $0.4-3.1$ & $0.80-6.7$ & 天然淡水 ${ }^{[13]}$ & $<5$ & & \\
\hline 红枫湖 ${ }^{[9]}$ & $2.5-13.9$ & $1.3-5.9$ & $1.2-8.0$ & 南极天然湖泊 ${ }^{[14]}$ & $0.4-1.9$ & & $0.1-0.4$ \\
\hline 阿哈湖 ${ }^{[10]}$ & $2.1-19.2$ & $0.3-14.8$ & $1.7-9.9$ & Wisconsin 湖泊 ${ }^{[15]}$ & $0.4-4.8$ & $0.1-1.3$ & $0.3-4.5$ \\
\hline 百花湖 ${ }^{[11]}$ & $6.9-110.6$ & $0.9-105.7$ & $2.7-8.2$ & Beverly 沼泽 ${ }^{[16]}$ & 2.0 & & \\
\hline 叶尼塞河 ${ }^{[12]}$ & & $0.2-1.2$ & $0.8-2.1$ & 鄂毕河 ${ }^{[12]}$ & $0.9-6.8$ & $2.4-3.2$ & \\
\hline
\end{tabular}

2.1.2 表层水体总甲基承、溶解态甲基承与颗粒态甲基承的分布 草海表层水体总甲基录浓度变化为 $0.11-0.67 \mathrm{ng} / \mathrm{L}$, 平均为 $0.25 \mathrm{ng} / \mathrm{L}$; 溶解态甲基永浓度范围为 $0.07-0.48 \mathrm{ng} / \mathrm{L}$, 平均为 $0.23 \mathrm{ng} / \mathrm{L}$; 颗粒态甲基 永浓度变化为 $0.02-0.26 \mathrm{ng} / \mathrm{L}$, 平均为 $0.05 \mathrm{ng} / \mathrm{L}$ (图 3). 丰水期表层水总甲基永浓度范围为 $0.11-0.67 \mathrm{ng} / \mathrm{L}$, 平均为 $0.25 \mathrm{ng} / \mathrm{L}(n=11)$; 枯水期表层水总甲基承浓度范围为 $0.36-0.65 \mathrm{ng} / \mathrm{L}$, 平均值为 $0.45 \mathrm{ng} / \mathrm{L}(n=5)$.

丰水期甲基录含量低于枯水期, 这可能是由于表层水体甲基录浓度受光辐射影响所致 ${ }^{[23]}$. 由于丰水 期水温较高 $\left(22.4^{\circ} \mathrm{C}\right)$, 光照条件充分, 光辐射强度比枯水期大, 因此表层水体中的甲基永容易被光分解还 原为二价录和零价采，从而降低了湖泊水体中甲基录的含量. 无论在丰水期还是枯水期，湖泊总甲基永 含量均表现为进口处高, 主要原因可能是进口处受人为活动等影响, 导致该区域录的净甲基化作用高于 其它水域而造成了水体高甲基永含量的特点.
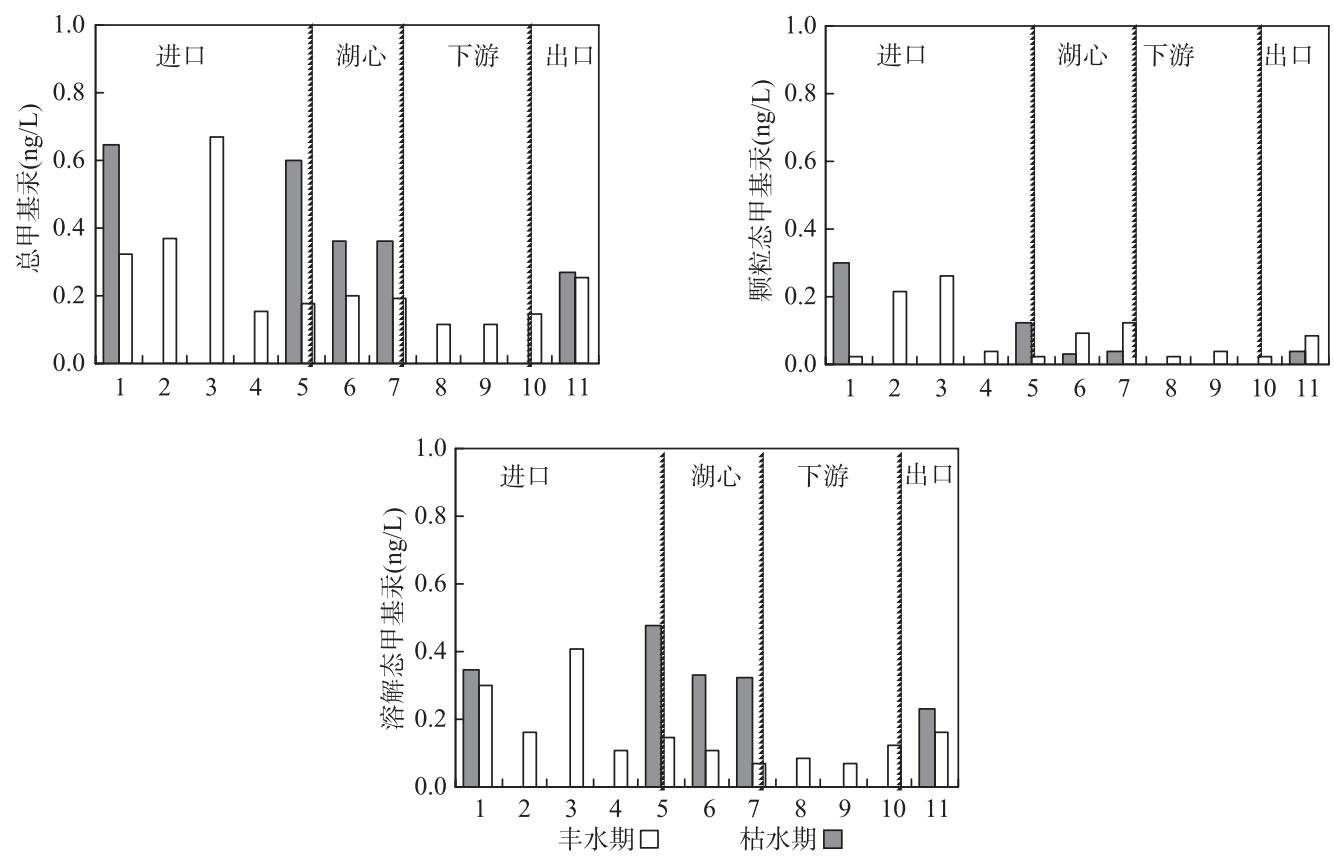

图 3 草海表层水体总甲基永、溶解态甲基永与颗粒态甲基永的分布

Fig.3 Distributions of MeHgT, MeHgD and MeHgP in surface water in Lake Caohai

草海表层水体甲基永占总采的比例分别为：丰水期 3\%-9\%，均值 6.7\%; 枯水期 4\%-11\%，均值 7.6\%. 总甲基录与总永含量之间无相关关系(丰水期 $r=0.592, n=11$; 枯水期 $r=-0.380, n=5$ ). 活性录在水体中可 
以转化为甲基永, 活性永的甲基化会大大增加录对生物的毒害程度. 草海表层湖水总甲基录与活性永无 明显的相关关系 (丰水期 $r=-0.002, n=11$; 枯水期 $r=-0.746, n=5$ ), 这可能暗示草海浅型湖泊的湖水中采的 甲基化作用不是很活跃，从而降低了其对湖泊生态系统的潜在危害.

丰水期溶解态甲基永浓度变化为 $0.07-0.41 \mathrm{ng} / \mathrm{L}$, 平均为 $0.16 \mathrm{ng} / \mathrm{L}(n=11)$; 枯水期溶解态甲基永浓度 变化为 $0.23-0.48 \mathrm{ng} / \mathrm{L}$, 平均为 $0.30 \mathrm{ng} / \mathrm{L}(n=5)$ (图 3). 草海水温与水体溶解态甲基永相关性表明, 丰水期呈 正相关关系 $(P<0.05)$, 枯水期无相关性 $(r=0.520, n=5)$; 而溶解氧(DO)与溶解态甲基永在不同季节均达到 显著负相关, 其中, 丰水期 $(P<0.01)$; 枯水期 $(P<0.05)$. 因此, 草海不同季节表层水体溶解态甲基永分布特 征, 可能受降雨量、水温、溶解氧、水生植物等共同影响结果 ${ }^{[24-25]}$.

溶解态甲基永是湖水中总甲基永的重要部分, 它的浓度很大程度上影响着甲基永的分布. 不同季节 草海表层水体溶解态甲基永占总甲基永的比例分别为: 丰水期 36\%-92\%, 平均为 67\%; 枯水期 56\%-81\%, 平均为 $66 \%$. 丰水期水体溶解态甲基永与总甲基永之间呈极显著相关(丰水期, $P<0.01$; 枯水期 $P<0.05$ ). 由此可见, 湖泊水体中的甲基永的产生和迁移与溶解态甲基永有密切的关系 ${ }^{[26]}$, 即草海表层湖水中总甲 基录的分布受溶解态甲基永的控制.

不同季节颗粒态甲基永含量均在进口处高(图 3). 主要是进口处受人为排污干扰影响, 悬浮物质等增 加，对录的吸附能力增强而导致颗粒态甲基永含量相对较高. 丰水期颗粒态甲基录均值为 $0.09 \mathrm{ng} / \mathrm{L}$ ，占 总甲基永的比例范围为 7\%-92\%, 平均为 34\%; 枯水期为 $0.10 \mathrm{ng} / \mathrm{L}$ ，占总甲基永的比例范围为 $20 \%-44 \%$, 平均为 $20 \%$. 其中, 总甲基录与颗粒态甲基永在丰水期达显著相关 $(P<0.01)$; 而枯水期却无相关性 $(r=0.322, n=5)$. 主要丰水期受强降雨量、悬浮颗粒物数量等共同因素影响.

\section{2 沉积物间隙水中不同形态录分布}

在枯水期, 人湖区沉积物间隙水溶解态总永浓度变化为 8.6-16.5ng/L, 平均为 $11.4 \mathrm{ng} / \mathrm{L}$. 在沉积物表 层下 $4 \mathrm{~cm}$ 处溶解态永具有峰值 $16.5 \mathrm{ng} / \mathrm{L}$ (图 4). 湖心区沉积物间隙水溶解态总永浓度变化为 $10.5-17.3 \mathrm{ng} / \mathrm{L}$,
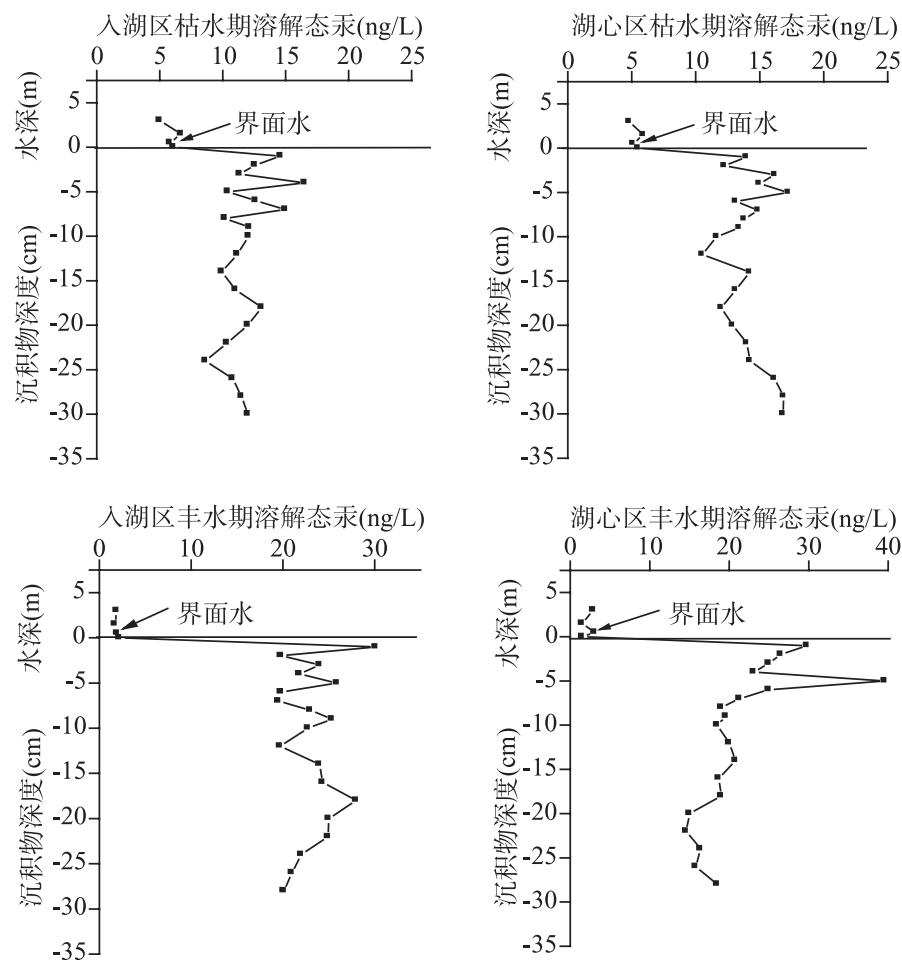

图 4 草海沉积物间隙水溶解态永的剖面分布

Fig.4 Distributions of $\mathrm{HgD}$ in sediment porewater profile in Lake Caohai 
平均为 $13.5 \mathrm{ng} / \mathrm{L}$, 溶解态录最大值出现在沉积物下 $5 \mathrm{~cm}$ 处; 在丰水期, 人湖区溶解态总录在 $19.5-30.1 \mathrm{ng} / \mathrm{L}$ 之 间, 平均为 $23.0 \mathrm{ng} / \mathrm{L}$; 湖心区溶解态总永在 14.6-39.6ng/L, 平均为 $21.2 \mathrm{ng} / \mathrm{L}$. 人湖区溶解态永最大值出现 在沉积物下 $1 \mathrm{~cm}$ 处, 随沉积深度逐渐降低. 而湖心区在沉积物 $5 \mathrm{~cm}$ 处出现峰值 $39.6 \mathrm{ng} / \mathrm{L}$, 随后逐渐降低 并趋于稳定. 总体而言, 沉积物间隙水溶解态永浓度 $(8.6-39.6 \mathrm{ng} / \mathrm{L}$, 平均为 $17.8 \mathrm{ng} / \mathrm{L}, n=39)$ 远高于上覆水 体中溶解态录浓度 $(0.8-6.7 \mathrm{ng} / \mathrm{L}$, 平均为 $3.9 \mathrm{ng} / \mathrm{L}, n=16)$, 沉积物与上覆水体间存在浓度梯度, 溶解态录将 从沉积物间隙水中向湖泊水体扩散.

草海沉积物间隙水溶解态甲基永剖面分布(图 5)可知，在枯水期，人湖区沉积物间隙水溶解态甲基永 浓度变化为 $0.11-0.58 \mathrm{ng} / \mathrm{L}$ 之间, 平均为 $0.29 \mathrm{ng} / \mathrm{L}$, 湖心区变化范围为 $0.20-0.65 \mathrm{ng} / \mathrm{L}$, 平均为 $0.34 \mathrm{ng} / \mathrm{L}$. 在 丰水期, 人湖区沉积物间隙水溶解态甲基永变化为 $2.2-4.9 \mathrm{ng} / \mathrm{L}$, 平均为 $3.1 \mathrm{ng} / \mathrm{L}$; 湖心区在 $2.4-4.8 \mathrm{ng} / \mathrm{L}$ 范 围之间, 平均为 $3.4 \mathrm{ng} / \mathrm{L}$.
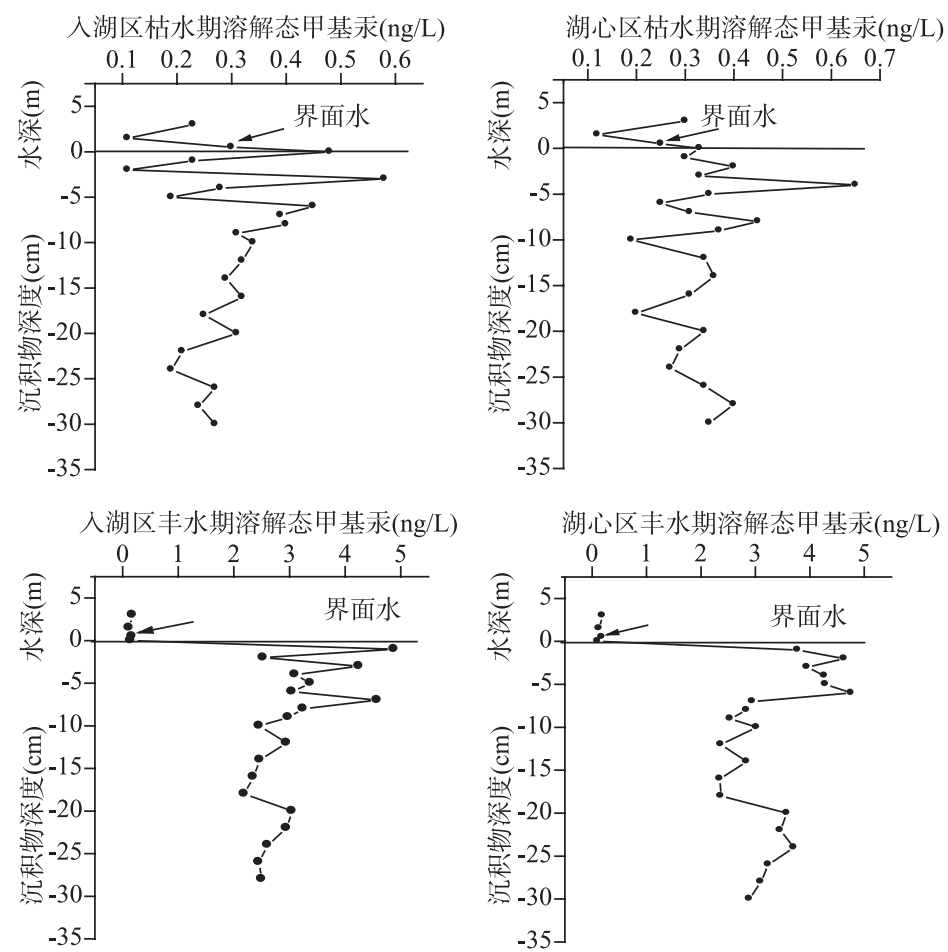

图 5 草海沉积物间隙水溶解态甲基永的剖面分布

Fig.5 Distributions of MeHgD in sediment porewater profile in Lake Caohai

沉积物间隙水中溶解态甲基永浓度明显高于上覆水体中溶解态甲基永浓度，即沉积物与上覆水体之 间存在浓度梯度，随着季节变化，夏季湖泊水体分层时，氧化还原边界层上移，间隙水中溶解态甲基永 会从沉积物向上覆水体扩散, 从而影响上覆水体甲基永的浓度 ${ }^{[27-28]}$.

\section{3 结论}

（1）草海表层水体总永浓度为 1.7-9.0ng/L，活性永浓度为 $0.06-1.4 \mathrm{ng} / \mathrm{L}$ ，甲基永浓度为 $0.11-0.67 \mathrm{ng} / \mathrm{L}$. 总永浓度高于世界天然淡水湖泊，存在一定程度录污染.

(2) 草海表层水体以溶解态永为主，溶解态永占总永的比例为枯水期 $87 \%$, 丰水期 $51 \%$, 溶解态永、颗粒态 采与总永均呈显著相关; 表层水体溶解态甲基永与总甲基永呈显著相关, 溶解态甲基永控制总甲基永的分布.

（3）草海沉积物间隙水溶解态录浓度为 8.6-39.6ng/L, 溶解态甲基录浓度为 $0.11-4.9 \mathrm{ng} / \mathrm{L}$, 沉积物间 隙水溶解态永与溶解态甲基永浓度远远高于上覆水体，成为草海湖水主要永来源之一. 


\section{4 参考文献}

[1] Lindqvist O, Johansson K, Bringmark L et al. Mercury in the Swedish environment-Recent research on causes, consequences and corrective methods. Water Air and Soil Pollut, 1991, 55(1-2): xi-261.

[2] Watras CJ, Frost TM. Little rock lake (Wisconsin): Perspectives on an experimental ecosystem approach to seepage lake acidification. Arch Environ Contam Toxicol, 1989, 18(1-2): 157-165.

[3] Huggett DB, Steevens JA, Allgood JC et al. Mercury in sediment and fish from North Mississippi Lakes. Chemosphere, 2001, 42(8): 923-929.

[4] 喻元秀. 草海高原湿地区域环境承载力研究[硕士论文]. 贵阳: 贵州师范大学, 2005.

[5] Feng X, Li G, Qiu G. A preliminary study on mercury contamination to the environment from artisanal zinc smelting using indigenous methods in Hezhang county, Guizhou, China-part1: mercury emission from zinc smelting and its influences on the surface waters. Atoms Environ, 2004, 38: 6223-6230.

[6] 王雨春, 黄荣贵. SWB-1 型便携式沉积物－界面水取样器的研制. 地球化学, 1998, 1: 94-96.

[7] 蒋红梅, 冯新斌, 梁 琖等. 蒸馏一乙基化 GC-CVAFS 法测定天然水体中的甲基录. 中国环境科学, 2004, 24(5) : 568-571.

[8] 围海鱼, 冯新斌, 商立海等. 天然水体中痕量永的形态分析方法研究. 分析测试学报, 2003, 22(5): 10-13.

[9] 何天容. 红枫湖永的地球化学循环研究[博士论文]. 贵阳: 中国科学院地球化学研究所, 2007.

[10] 白薇扬. 阿哈水库中不同形态录迁移转化研究[硕士论文]. 贵阳: 中国科学院地球化学研究所, 2006.

[11] 间海鱼. 贵州百花湖录的生物地球化学循环特征的初步研究[博士论文]. 贵阳: 中国科学院地球化学研究所, 2005.

[12] Coquery M, Cossa D, Martin JM. The distribution of dissolved and particulate mercury in three Siberian estuaries and adjacent Arctic coastal waters. Water Air and Soil Pollut, 1995, 80(1-4): 653-664.

[13] Bloom N. Determination of picogram levels of methylmercury by aqueous phase ethylation, followed by cryogenic gas chromatography with cold vapour atomic fluorescence detection. Can J Fish Aquat Sci, 1989, 46(7): 1131-1140.

[14] Watras CJ, Bloom NS, Claas SA et al. Methylmercury production in the anoxic hypolimnion of a dimictic seepage lake. Water Air Soil Pollut, 1995, 80(1-4): 735-745.

[15] Benoit JM, Mason RP, Gilmour CC et al. Constants for mercury binding by dissolved organic matter isolates from the Florida Everglades. Geochim Cosmochim Acta, 2001, 65(24): 4445-4451.

[16] Galloway ME, Branfireun BA. Mercury dynamics of a temperate forested wetland. Sci Total Environ, 2004, 325(1-3): 239-254

[17] Feng X, Hong Y. Modes of occurrence of mercury in coals from Guizhou, People's Republic of China. Fuel, 1999, 78(10): 1181-1188.

[18] 冯新斌. 环境样品中微量录的分析方法及贵州省二叠纪龙潭组煤炭中采的分布规律、赋存状态 [博士论文]. 贵阳: 中国科 学院地球化学研究所, 1997 .

[19] 李广辉, 冯新斌, 仇广乐. 贵州省赫章县土法炼锌过程中录的释放量的初步研究. 环境科学学报, 2005, 25(6): 836-839.

[20] Guimaraes JRD, Meili M, Malm O et al. $\mathrm{Hg}$ methylation in sediments and floating meadows of a tropical lake in the Pantanal floodplain, Brazil. Sci Total Environ, 1998, 213(1): 165-175.

[21] Lindberg SE, Zhang H. Air/water exchange of mercury in the Everglades II: measuring and modeling evasion of mercury from surface waters in the Everglades Nutrient Removal Project. Sci Total Environ, 2000, 259(1-3): 135-143.

[22] Ullrich SM, Tanton TW, Abdrashitova SA. Mercury in the aquatic environment: a review of factors affecting methylation. Crit Rev Environ Sci Technol, 2001, 31(3): 241-293.

[23] Seller P, Kelly CA, Rudd JWM et al. Photodegradation of methylmercury in lakes. Nature, 1996, 380: 694-697.

[24] Bisogni JJJr, Lawrence AW. Kinetics of mercury methylation in aerobic and anaerobic aquatic environments. $J$ Water Pollut Control Fed, 1975, 47(1): 135-152.

[25] Kotnik J, Horvat M, Fajon V et al. Mercury in small freshwater lakes: a case study: Lake Velenje, Slovenia. Water Air Soil Pollut, 2002, 134(1-4): 317-337.

[26] Gilmour CC, Henry EA. Mercury methylation in aquatic systems affected by acid deposition. Environ Pollut, 1991, 71(2-4): 131-169.

[27] 万 曦, 万国江, 黄荣贵等. 阿哈湖 Fe, Mn 沉积后在迁移的生物地球化学机理. 湖泊科学, 1997, 9(2): 9-14.

[28] 白薇扬, 冯新斌, 孙 力等. 贵阳市阿哈湖水体和沉积物间隙水中录的含量和形态分布初步研究. 环境科学学报, 2006, 26(1): 91-98. 